\title{
Leprosy: between acceptance and segregation. Community behaviour towards persons affected by leprosy in eastern Nepal
}

\author{
D. H. de STIGTER, L. de GEUS \& M. L. HEYNDERS \\ NSL Eastern Leprosy Control Project, PO Box 134, Biratnagar, \\ Nepal; Maastricht University, Faculty of Health Sciences, Department \\ of Health Education, PO Box 616, 6200 MD Maastricht, The Netherlands
}

\begin{abstract}
Summary This study describes community behaviour towards persons affected by leprosy in the eastern Terai districts of Nepal. The results show that $95 \%$ of the persons affected by leprosy recognized by the community have visible signs such as wounds, swellings and deformed feet or hands. Persons affected by leprosy still experience negative behaviour. Motives for negative community behaviour are mostly found in the fact that people fear infection by germs, but fear of a curse from God is also mentioned. This study shows that negative community behaviour is still present in eastern Nepal. Leprosy is more than a disease; the disease can nowadays be medically cured, but the sickness of leprosy still remains. Leprosy control programmes should focus on prevention of impairments and disabilities, because it seems that a visible sign is an important trigger for negative community behaviour.
\end{abstract}

\section{Introduction}

Leprosy is more than a biological disease, it is also characterized by social stigma. The origin of social stigma is found in individuals who have certain attributes that do not concur with the prevailing standards of the normal and good in a group. Stigmatized individuals are treated by society in a negative way.

According to Robinson, ${ }^{1}$ leprosy can be explained in terms of disease (biomedical perception), illness (self-perception) or sickness (social perception). In this tripartite it is the term sickness that reflects the social stigma. In the case of leprosy, health workers tell patients that they have the disease leprosy according to physical symptoms. The illness leprosy is experienced by the person and this is shaped by social and cultural influences. The sickness leprosy, is the problem as perceived and named by the society, expressed into social stigma. ${ }^{2}$

In Nepal it seems that persons affected by leprosy have tried to hide their disease, out of fear of negative community behaviour. They stop going to the clinic (non-compliance), which

Correspondence to: M.L. Heynders, Maastricht University, Faculty of Health Sciences, Department of Health Education, PO Box 616, 6200 MD Maastricht, The Netherlands 
seems one of the defence mechanisms to conceal their disease and thus to maintain their social integrity ${ }^{3-5}$

The major problem the Eastern Leprosy Control Program in Nepal has to deal with is this high non-compliance rate which has remained stable over the past 5 years at more than $40 \% .^{6}$ Looking into the problem of non-compliance, the following three levels were identified to reduce it; the leprosy programme, the person affected by leprosy, and the community. If at any level something is not going well this will influence decisions taken at another level and lead eventually to non-compliance of the patients. For example at programme level, medication must be available and the quality of care must be good. Motivation at the other hand is important at patient level, which can be influenced by the attitude of the community. The studies conducted at programme level ${ }^{3}$ and patient level ${ }^{4}$ showed that persons affected by leprosy have tried to hide their disease out of fear for negative community behaviour. In this way, stopping going to the clinic (non-compliance) can be seen as one of the defence mechanisms used by patients to conceal their disease and thus to maintain their social integrity. ${ }^{5}$ However, it is not clear if such fear of negative community behaviour is based on stories from the past or on actual experience.

Lots of terrible stories about negative community behaviour are known; persons affected by leprosy were reported to have been buried or burned alive. Other research shows that persons affected by leprosy experience exclusion from social life. ${ }^{7}$ For example, they have to sit and eat separately and are not allowed to use public facilities. ${ }^{7,8}$ They have difficulties in gaining employment or they are refused jobs. ${ }^{9-13}$ Younger persons affected by leprosy suffer from restrictions at schools. ${ }^{7}$ In general persons affected by leprosy experience unsympathetic reactions, insults, hate, abandonment or rejection. ${ }^{8-11}$ Community members also favour some form of segregation; they want persons affected by leprosy to be kept and treated away from their homes and villages. ${ }^{12,15}$

Unfortunately, no recent data about community behaviour in Nepal, towards persons affected by leprosy were available. The existing research about community behaviour describes community behaviour from more than 5 years ago. Furthermore, most studies do not specify when the events took place. Persons affected by leprosy and not community members are usually interviewed about the experienced community behaviour. As a result, reasons for community behaviour have rarely been investigated. Moreover, most persons have been interviewed in leprosaria, which does not reflect the situation in the community. Many leprosaria are closed nowadays, so these reports do not represent the actual situation at present.

Therefore, this study investigates how communities behave towards persons affected by leprosy in eastern Nepal today and whether fear for negative community behaviour is based on actual behaviour. Furthermore, this research looks into the motives for community behaviour. Based on the results of this study, recommendations to reduce the defaulter rate will be presented.

\section{Materials and methods}

The study was conducted in Nepal, in the Eastern Leprosy Control Project (ELCP), a cooperation between His Majesty's Government (HMG) and the Dutch Leprosy Relief Association (NLR). In Nepal the leprosy control programme has been integrated into the basic health services since 1987. Hence persons affected by leprosy are predominately diagnosed and treated at the primary health care level. 
Three hundred community members were selected at random in five communities in eastern Nepal (Golbazaar, Barsain, Rangeli, Kuwarkhod and Bhadrapur). Two teams, each consisting of two field workers, interviewed the community members. During the interview notes were made. The research instrument was pre-tested and is shown in Appendix 1.

The community members were asked to tell about community behaviour towards a particular person they knew was affected by leprosy. Asking somebody directly about his own behaviour can result in their giving social acceptable answers; therefore the interviewer asked about behaviour other community members showed towards the patient.

In this way 192 narratives about community behaviour towards persons affected by leprosy were collected. These narratives describe what is told today and give a picture of the past and the situation at present.

\section{Results}

RESPONDENTS

Three hundred community members (respondents) were interviewed: 148 men and 152 women. The majority of the respondents was between 21 and 55 years old (73\%). The largest group (84\%) of them was Hindu. Due to the complexity of the Nepali caste and ethnic group system it was not possible to categorize these data.

Among the 300 community members, 57\% could tell about actions taken towards one or two patients they knew, $23 \%$ did not know any of the local names for leprosy, $18 \%$ knew about leprosy, but were not able to tell about a person affected by leprosy and $2 \%$ did not have time to do an interview.

\section{PATIENTS}

In total, the respondents could tell about 192 persons affected by leprosy: 144 men and 48 women $(75 \%$ and $25 \%$, respectively). The majority of persons affected by leprosy were found in the age group between 21 and 55 years old (62\%) and again the largest group was Hindu $(87 \%)$.

Looking at the signs the respondents mentioned in the narratives it is seen that: $5 \%$ had no visible signs of leprosy, $10 \%$ had only patches or skin rash, $7 \%$ had blackness or swelling and $78 \%$ had visible deformities or wounds. This means that the majority of the narratives were about persons having deformities and $95 \%$ of the persons affected by leprosy has visible signs.

\section{COMMUNITY BEHAVIOUR}

Community behaviour mentioned during this study is categorized into the following groups; 'usual behaviour' and four categories dealing with negative behaviour: 'eating limitations', 'individual negative behaviour', 'social-public restrictions' and 'segregation' (Table 1).

The categories had a certain degree of severity, starting with 'eating limitations' and ending with 'segregation'. Persons affected by leprosy were categorized in the group of the most severe behaviour they experienced. For example, a person affected by leprosy who experienced 'eating limitations' and 'social-public restrictions' is placed in group 3. During the pre-test not only negative community behaviour has been found, but also usual behaviour. 
Table 1. Categories of community behaviour groups

Group 1 Eating limitations

Group 2 Individual negative behaviour

Group 3 Social-public limitations

Group 4 Segregation

Group 5 Usual behaviour
People do not eat food touched by person affected by leprosy ('jutho'), person affected by leprosy has to eat separately

Person affected by leprosy has to sit separately, is not allowed to enter homes, people do not visit, is hated or ignored, is not allowed to touch Person affected by leprosy is not allowed to use public well, not allowed to enter temple, not allowed at school, not allowed in social functions, not allowed to attend festivals, not allowed to use public facilities, not allowed to enter the teashop, problems to get medical care, problems in job, everything separately

Send out of village

Person affected by leprosy is allowed to enter homes, everything together, being treated well

A separate group, 'usual behaviour' (group 5), was included for those persons affected by leprosy who did not experience any negative behaviour; they are treated well or the community does everything together with them.

In this research, community behaviour has been divided into different time periods. First, the distinction has been made in behaviour that happened more than 20 years ago, because a period of 20 years is considered to reflect one generation in Nepal. Second, the period ' 0 to $\leq 5$ years' reflects behaviour which have been shown recently. Finally, the community behaviour of the last year have been described separately, to present reliable information and to show what happens nowadays.

Table 2 shows that there has been a trend that during the last 20 years; negative behaviour seems to decrease while usual behaviour seems to increase. Usual behaviour means that community members refrain from negative behaviour. It does not mean that they give real support. It is interesting that no differences towards male and female persons affected by leprosy are found. Furthermore, negative behaviour only ended when a person affected by leprosy died. This occurred in 23 cases.

Table 3 shows that it is hard to distinguish a trend in specific behaviour over the years. However, when we compare the period ' 5 to $\leq 20$ years' to ' 0 to $\leq 5$ years', it seems that negative treating behaviour increases while social public restrictions and segregation decreases. Although segregation decreases, even last year three persons affected by leprosy were sent out of their village.

Table 2. Percentages of negative and usual community behaviour groups, in relation to starting time $(n=186)^{*}$

\begin{tabular}{|c|c|c|c|c|c|}
\hline & $\begin{array}{c}>20 \text { years } \\
n(\%)\end{array}$ & $\begin{array}{c}5 \text { to } \leq 20 \text { years } \\
n(\%)\end{array}$ & $\begin{array}{c}0 \text { to } \leq 5 \text { years } \\
n(\%)\end{array}$ & $\begin{array}{c}0 \leq 1 \\
(n=23)\end{array}$ & $\%$ \\
\hline Negative behaviour (groups 1, 2, 3, 4) & $10(83)$ & $58(67)$ & $57(65)$ & 12 & 52 \\
\hline \multirow[t]{2}{*}{ Usual behaviour (group 5) } & $2(17)$ & $28(33)$ & $31(35)$ & & \\
\hline & & & & 11 & 48 \\
\hline \multirow[t]{2}{*}{ Total } & $12(100)$ & $86(100)$ & $88(100)$ & 23 & \\
\hline & & & & 0 & \\
\hline
\end{tabular}

\footnotetext{
* Six persons affected by leprosy missing.
} 
Table 3. Percentage of negative community behaviour groups, in relation to starting time $(n=125)^{*}$

\begin{tabular}{lcccc}
\hline & $\begin{array}{c}>20 \text { years } \\
n(\%)\end{array}$ & $\begin{array}{c}5 \text { to } \leq 20 \text { years } \\
n(\%)\end{array}$ & $\begin{array}{c}0 \text { to } \leq 5 \text { years } \\
n(\%)\end{array}$ & $\begin{array}{c}0 \text { to } \leq 1 \text { year } \\
n(\%)\end{array}$ \\
\hline Group 1 Eating limitations & - & $3(5))$ & $2(4)$ & - \\
Group 2 Negative behaviour & $4(40)$ & $12(21)$ & $24(42)$ & $6(50)$ \\
Group 3 Social-public limitations & $4(40)$ & $29(50)$ & $23(40)$ & $3(25)$ \\
Group 4 Segregation & $2(20)$ & $14(24)$ & $8(14)$ & $3(25)$ \\
Total negative behaviour & $10(100)$ & $58(100)$ & $57(100)$ & $12(100)$ \\
\hline
\end{tabular}

* Data on four persons affected by leprosy are missing.

\section{MOTIVES}

Motives reported for rejection are mostly found in the fact that respondents think that leprosy is a very contagious disease. Others are afraid of the curse of God, whereas there are also community members who mention both motives as the reason for their behaviour. On the other hand, motives for acceptance depend on the benevolence of the community and on the characteristics of the person affected by leprosy (for example the person affected by leprosy is a child or important community member). Other motives for usual behaviour are that the person affected by leprosy takes medication or that people think that leprosy is not infectious.

\section{Discussion}

It is obvious that $77 \%$ of the community members know what leprosy is. This is in contradiction with the suspected lack of knowledge about leprosy.

Leprosy seems to be recognized through deformities because more than three-quarters of the narratives are about persons affected by leprosy with deformities. Persons affected by leprosy with deformities are more likely to experience negative community actions than persons affected by leprosy without deformities. Therefore, Prevention of Impairments and Disabilities should get high priority in the leprosy programme.

It was expected that during the last 20 years negative community behaviour would have decreased. Unfortunately, the research shows that negative community behaviour is still present. Even nowadays persons affected by leprosy have to leave their village or are socially isolated. Therefore, it is understandable that persons affected by leprosy try to hide their disease out of fear of negative community actions.

Table 4. Motives for community behaviour

\begin{tabular}{lrll}
\hline Motives for negative behaviour & $\%$ & Motives for unusual behaviour & $\%$ \\
\hline Fear of infection by germs & 64 & No fear of infection by germs & 20 \\
Fear of curse of God & 9 & Person takes medication (MDT) & 27 \\
Infection by germs and curse of God & 18 & Benevolence of community & 24 \\
Other & 9 & Characteristics of patient & 16 \\
& & Other & 13 \\
\hline
\end{tabular}


Many community members mentioned 'fear of infection by germs' as motive for their behaviour. We also see that community members mention both 'fear of infection by germs' and 'fear of curse of God' as motive for their behaviour. In these cases the perception of the aetiology of leprosy is completely different. It is interesting to see that both ways of interpretation exist at the same time. In Nepal, this dualism is also seen in health seeking behaviour. People often go to traditional healers as well as western doctors, sometimes even at the same time ${ }^{2,16}$. When we want to reduce the negative behaviour towards persons affected by leprosy, we have to take this dualism into account. Communities should not only be informed about the (Western understanding) of transmission and treatment, but traditional thoughts should also be discussed.

Other research ${ }^{8,14}$ reports that women experience more negative community behaviour than men, however, in this study, no differences between men and women were found. It was expected that in Nepal women would experience more negative behaviour because in daily life women have fewer privileges than men. It is the sickness leprosy which results in negative community behaviour.

In conclusion, the results of this study show that fear of negative community behaviour of persons affected by leprosy is based on actual events. Persons affected by leprosy still experience many limitations and restrictions in their social life, and segregation still occurs. It is therefore very understandable that patients try to hide their disease and therefore stop going to the clinic (non-compliance) or delay seeking help. Leprosy is more than a disease, the disease leprosy can nowadays medically be cured in 1 year, but the sickness (the social perception of leprosy) still remains.

It seems that in the community leprosy is recognized through deformities. Therefore, Prevention of Impairments and Disabilities should be a priority. Health education campaigns should not only focus on signs and symptoms, but communities should also be informed about the (Western) understanding of transmission and treatment, and traditional thoughts should be discussed. In conclusion, leprosy control programs should focus on the acceptance of the sickness leprosy, so that persons affected by leprosy would no longer feel uncomfortable in going to the clinic and would not lose any privileges of social life.

\section{Acknowledgements}

We would like to thank Dr K. P. Dhakal and Dr J. J. Meijs, project leaders of the Eastern Leprosy Control Project in Nepal, for the opportunity to conduct this study. We are also grateful to the field investigators for data collection. Furthermore we would like to thank the community members of Golbazaar, Barsain, Rangeli, Kumarkhod and Bhadrapur for their participation in the interviews.

\section{References}

1 Robinson I. Personal narratives, social careers and medical courses. Social Science and Medicine, 1990; 30:11731186.

2 Valencia LB. XIII Leprosy congress state-of-the-art lecture. Social science research on social dimensions of leprosy. Where are we going from here? Int. J. Lepr., 1989; 57: 847-863.

3 Heynders ML. Assessment of users' and providers' satisfaction with the leprosy services in eastern Nepal. NSL Office, Biratnagar, 1997. 
${ }^{4}$ Heynders ML. Defaulter study, in the Eastern NSL Terai districts in Nepal. NSL Office, Biratnagar, 1997.

${ }^{5}$ Heyland JE. A socio-cultural study of leprosy in Nepal: compliance, patient illness, correct patterns and health education. Doctoral Thesis, University of Tasmania.

HMG. Leprosy Control Division, HMG. Department of Health Services, Nepal, 1997

${ }^{7}$ Kant VP. Socio-economic problems of leprosy patients and their relatives in Gujarat State. Ind. J. Lepr., 1984; 56: 889-900.

${ }^{8}$ Ulrich M, Zulueta AM, Caceres-Dittmar G et al. Leprosy in women: characteristics and repercussions. Soc. Sci. Med., 1993; 37: 445-456.

9 Mull JD, Wood CS, Gans LP, Mull DS. Culture and compliance among leprosy patients in Pakistan. Soc. Sci. Med., 1989; 29: 799-811.

${ }^{10}$ Myint T, Tun Thet A, Thet Htoon M, Wim M. A comparative KAP study of leprosy patients and members of the community in Hlang and Laung township. Ind. J. Lepr., 1992; 63: 213-217.

11 Kumaresan JA, Maganu ET. Socio-cultural dimensions of leprosy in North Western Botswana. Soc. Sci. Med., 1994; 39: 537-541.

12 Raju MS, Kopparty SNM. Impact of knowledge of leprosy on the attitude towards leprosy patients: a community study. Ind. J. Lepr., 1995; 57: 620-623.

13 Naik SS, Hambarde PS, Desas AN. Problems and needs of women leprosy patients in Bombay and Goa - a preliminary report. Ind. J. Lepr., 1991; 63: 213-217.

14 Rao S, Garole V, Walawalkar S et al. Gender differences in the social impact of leprosy. Lepr. Rev., 1996; 67: 190-199.

15 Shetty JN, Shivaswamy SS, Shirwadkar PS. Knowledge, attitude and practices of the community and patients regarding leprosy in Mangalore - a study. Ind. J. Lepr., 1985; 57: 613-619.

16 Kristvik, E. Drums and syringes. Unpublished thesis, 1993.

17 Stigter DH de. Leprosy: between acceptance and segregation. Community behaviour towards patients with leprosy in eastern Nepal. Maastricht University, Maastricht, 1996.

Appendix 1. Research instrument ${ }^{17}$

1. Introduction.

2. Demographic variables of interviewee (name, age, sex, caste, ethnic group, religion).

3. Leprosy awareness of the interviewee. Has the interviewee heard of the following diseases?

- Charma rog, Kustha rog, Maha rog, Kord, Soon bairi, Dheen dha (local names for leprosy).

- How many patients does he know with one of these 'diseases'?

- Can the interviewee tell something about one patient? (maximum three patients).

- What is the relation with the patient?

4. Demographic variables of the person affected by leprosy (name, age, sex, marital status, family type, caste, ethnic group, religion).

5. Leprosy symptoms of the person affected by leprosy.

6. Community actions towards the patient. For every action ask: when?, why?

7. Remarks. 